\title{
Detalhes singulares nos procedimentos operacionais da disjunção palatina
}

\author{
Orlando TANAKA*, Bruno ORELLANA**, Gerson RIBEIRO***
}

\section{Resumo}

A disjunção palatina traz benefícios significativos nas más oclusões caracterizadas pela atresia esquelética do arco dentário superior. Desde os tempos de Angell muitos manuais foram criados com o intuito de orientar a instalação de aparelhos construídos em diferentes formatos e com materiais dos mais diversos fabricantes, utilizando, ainda, diferentes protocolos de ativação que objetivam a referida correção. A tecnologia utilizada para melhorar os materiais componentes dos aparelhos ortodônticos é muito importante mas os pequenos detalhes, que na verdade, não são pequenos, aliados aos conhecimentos científicos e ao bom senso devem ser observados, pois não se deve esperar que o aparelho "faça e resolva" tudo, corrigindo "num passe de mágica" as mordidas cruzadas posteriores. Este trabalho tem por objetivo detalhar as minúcias globais importantes, seja na confecção, na ativação e nos cuidados durante a permanência do disjuntor palatino na cavidade bucal.

Palavras-chave: Disjunção palatal. Aparelho de Haas. Expansão rápida da maxila

\section{INTRODUÇÃO}

A idéia de expandir o palato por meio da separação da sutura palatina mediana foi, primeiramente, concretizada por Angell, em 186020. Não por acaso, nesta ocasião, um dos primeiros detalhes observados foi o diastema entre os incisivos centrais superiores, sinal clínico do sucesso ortopédico deste procedimento. $\mathrm{Na}$ ocasião da análise do trabalho para a publicação, os editores da revista Dental Cosmos não acreditaram no efeito ortopédico de abertura da sutura palatina mediana que o disjuntor proporcionava e além de modificarem a ilustração de Angell (Fig. 1A, 1D) que mostrava o diastema interincisivos centrais superiores, fizeram um editorial duvidando do seu feito. Até os dias atuais há profissionais que não se aproveitam dos benefícios de estabilidade e segurança fornecidos pelo procedimento de disjunção palatina.

O tratamento ortopédico com o aparelho disjuntor palatino tipo Haas, para a correção de mordidas cruzadas posteriores com atresias maxilares (Fig. 2A-2D), foi reintroduzido no meio ortodôntico no final da década de $50^{5,8}$, mas teve início, como procedimento de rotina para a dentição permanente, na década de $60^{\circ}$. A partir da década de 80 , variações na estrutura do aparelho possibilitaram o seu emprego em dentições decídua e mista ${ }^{4}$, 18,19 , fazendo com que o emprego do protocolo de

* Professor Titular - CCBS - PUCPR - Doutor em Odontologia - Ortodontia FO-UFRJ

** Pós-Graduando em Odontologia - Ortodontia do Programa de Pós-Graduação da PUCPR.

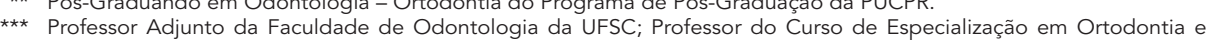
Ortopedia Facial da UFSC. 
disjunção palatina em crianças se popularizasse. A sua característica original que é a de ser um aparetho de ancoragem máxima, com apoio dento-muco suportado, foi mantida, preservando a identidade do aparelho, fator fundamental para o seu resultado ortopédico. Com relação aos elementos de suporte e/ou ancoragem às forças do disjuntor palatino, $\mathrm{Haas}^{7}$, fez a seguinte classificação:

Unidades de Ancoragem: $\mathrm{Na}$ dentição permanente (primeiros molares e primeiros pré-molares) e na dentição decídua ( ${ }^{\text {os }}$ molares permanentes ou $2^{\text {os }}$ molares decíduos e caninos decíduos).

Unidades de Resistência: abóbada palatina, processos alveolares, dentes e fibras periodontais.

Apesar de ter seu emprego aprovado e consagrado como um meio confiável para se corrigir mordidas cruzadas posteriores na fase da dentição decídua (Fig. 3A), mista (Fig. 3B,C) e permanente (Fig. 3D), a construção do aparelho requer certos cuidados imprescindíveis para que os objetivos sejam alcançados. Tais cuidados não são freqüentemente relatados na literatura e, quando o são, carecem de uma explanação criteriosa e detalhada.

O propósito deste trabalho é salientar e ilustrar alguns detalhes que devem ser observados no procedimento de disjunção palatina com o aparelho disjuntor tipo Haas modificado, que não são freqüentemente encontrados na literatura. Esses detalhes são pertinentes tanto à fase laboratorial de confecção do aparelho (Fig. 4, 6, 7, 8) como a recomendações a paciente e/ou responsável para
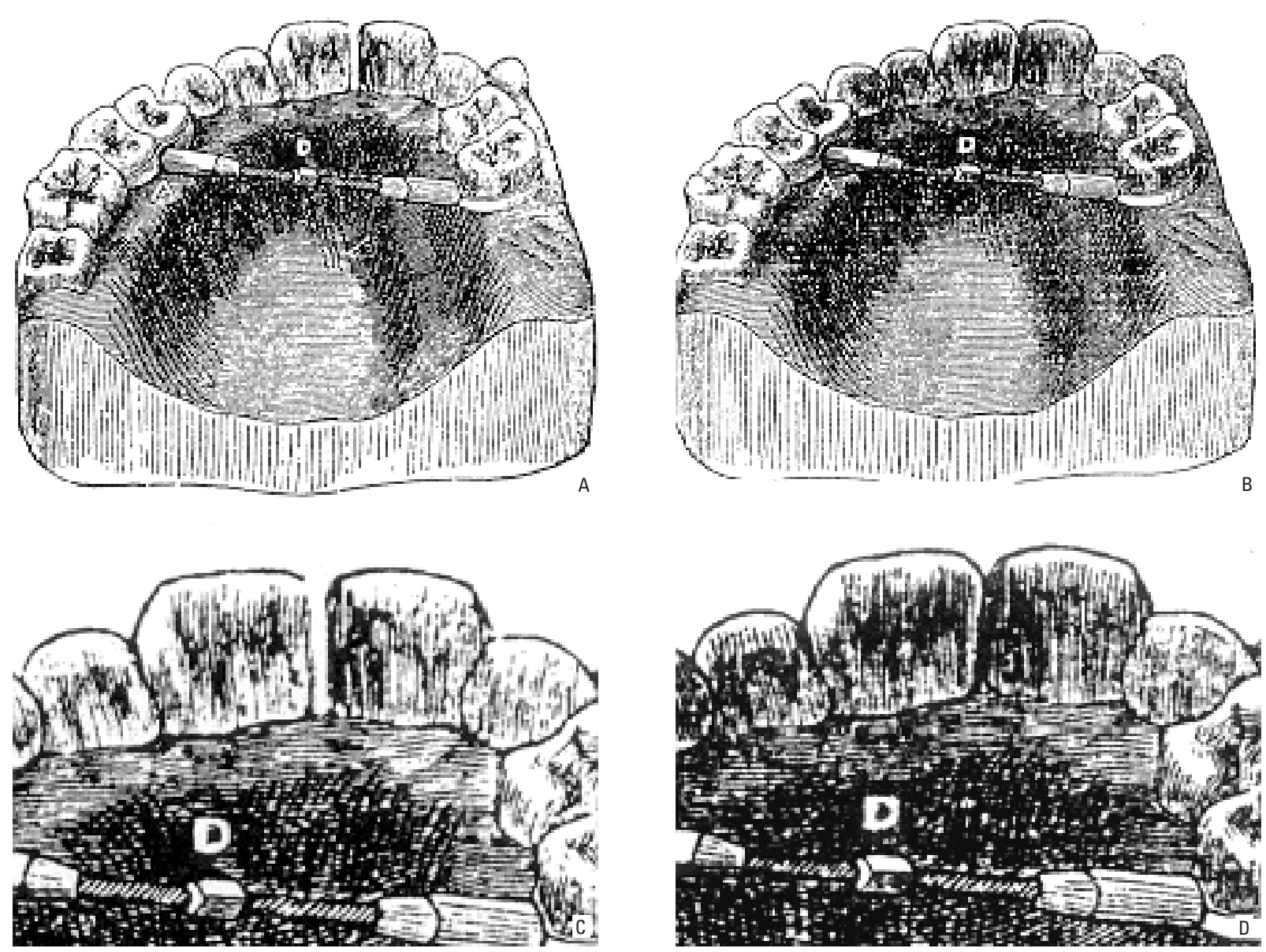

FIGURA 1 - A-C) Aparelho preconizado por Angell e publicado inicialmente no San Francisco Medical Press, mostrando o diastema interincisivos centrais. B-D) 0 mesmo aparelho e o mesmo aparelho sem o diastema, publicado no Dental Cosmos (1860). 

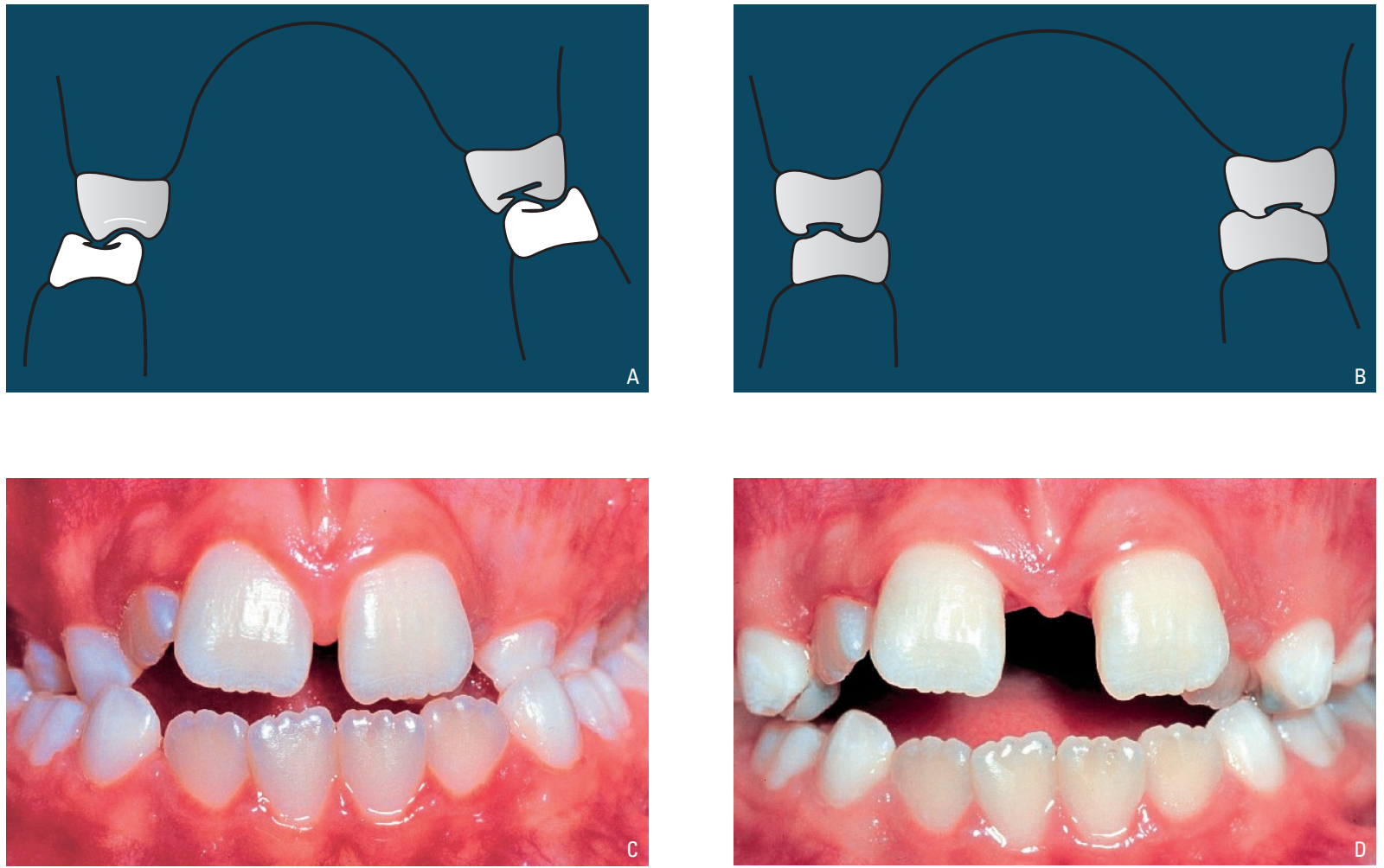

FIGURA 2 - A) Desenho esquemático da mordida cruzada posterior de caráter esquelético. B) Relação transversal normal. A modificação da base óssea maxilar, compatibilizando-a com a mandíbula é proporcionada pela disjunção palatina. C) Mordida cruzada posterior de caráter esquelético, na fase da dentição mista. D) Mordia cruzada corrigida por meio da disjunção palatina. 0 diastema entre os incisivos centrais superiores é o sinal clínico do efeito ortopédico.
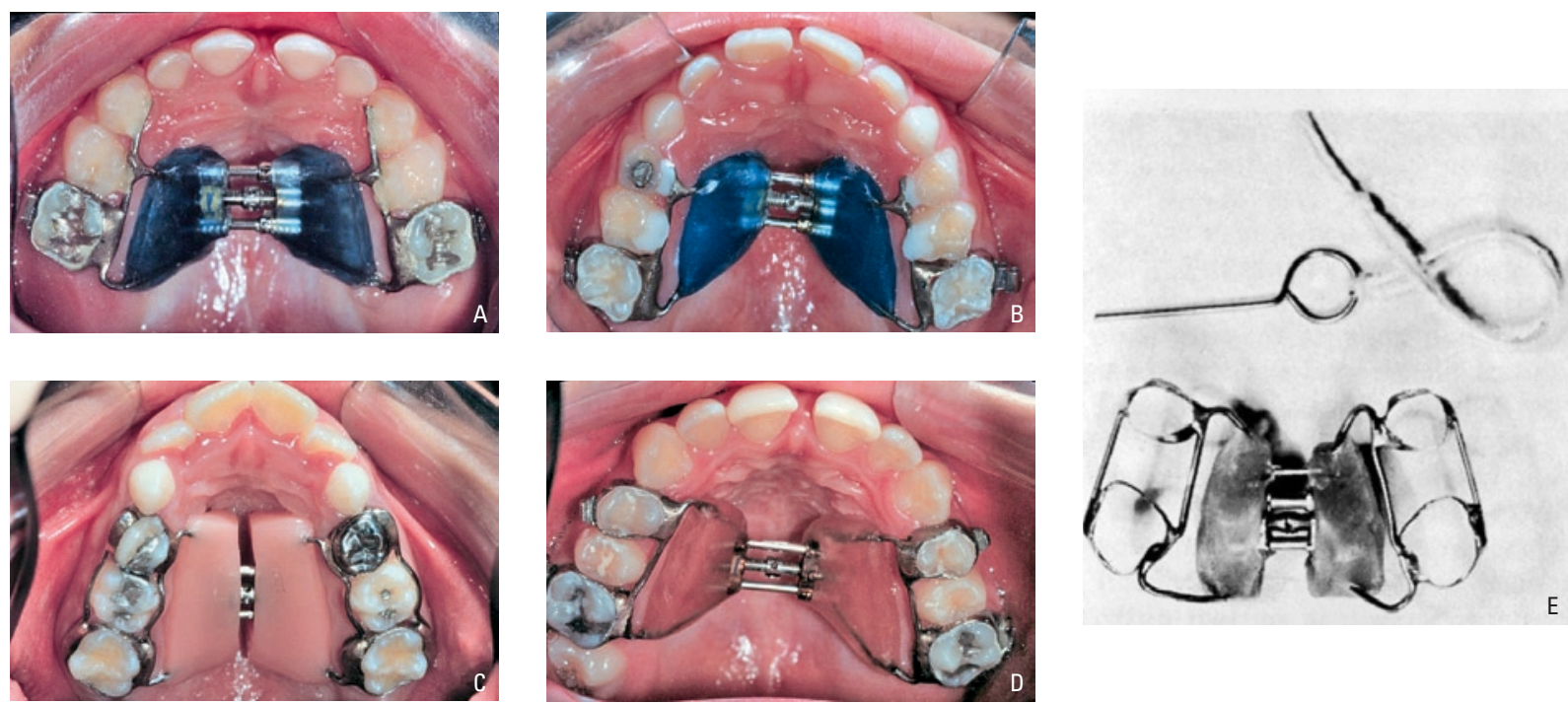

FIGURA 3 - A) Disjuntor palatino modificado, preconizado na fase da dentição decídua. B) Fase da dentição mista. C) Disjuntor palatino com bandas também nos ${ }^{\text {os }}$ molares decíduos. D) Disjuntor palatino na fase da dentição permanente. E) Disjuntor palatino preconizado por Haas. 

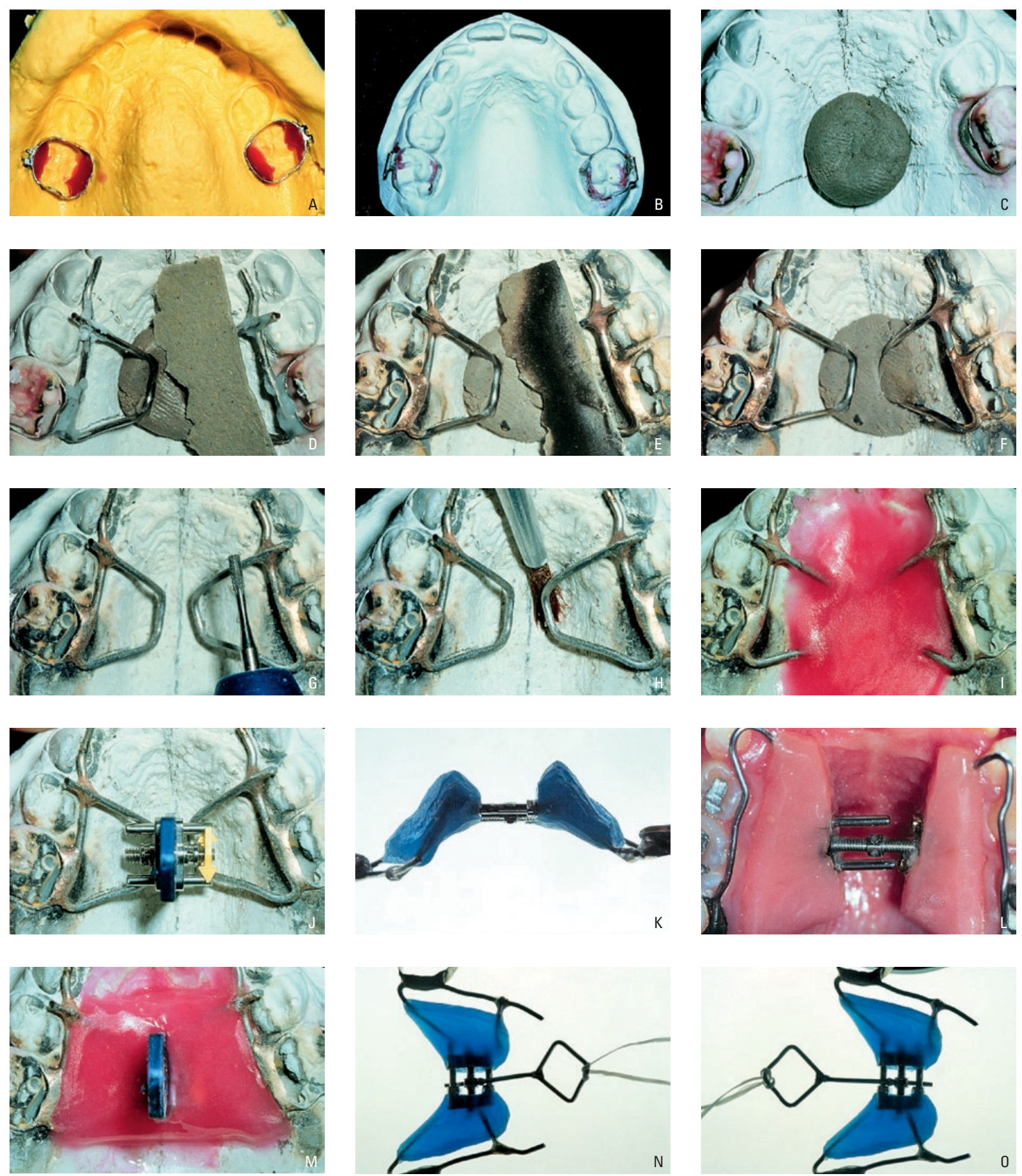

FIGURA 4 - A) Posicionamento das bandas ortodônticas, com acessórios soldados na vestibular, adaptadas previamente nos molares superiores no molde. Aplicação de cera rosa número 7, em fase plástica, para retenção e facilitar a soldagem. B) modelo de trabalho com as bandas ortodônticas posicionadas em seus respectivos dentes. C) Inserção de "moldine" no centro da abóbada palatina para posicionar e fixar as barras de conexão e manter afastadas cerca de 2 a $3 \mathrm{~mm}$ da mucosa palatina. D) Barras conectoras confeccionadas com fio de aço de 1 ou 1,2mm, posicionadas e fixas com "moldine" e aplicação de fluxo nas áreas que receberão as soldas de prata. E) adaptação de lâmina de amianto para a proteção das áreas adjacentes à soldagem e áreas de recepção de acrílico. F) Barras conectoras soldadas às bandas ortodônticas.. G) Limpeza da região da oxidação após a soldagem com uma broca de baixa rotação. H) Isolamento do modelo para receber o acrílico autopolimerizável. I) Inserção do acrílico antes da fase de trabalho. Neste ponto, inserir, também, o parafuso. J) A seta de orientação deve estar voltada para a distal. K) Parafuso totalmente aberto para verificar a quantidade de abertura. L) Parafuso espanado devido à abertura excessiva e não devidamente controlada. M) Posicionar o parafuso sobre a sutura palatina mediana perpendicular ao palato e paralelo aos dentes. N-0) Posicionamento do parafuso antes e depois da ativação do parafuso. 
com os cuidados no momento da ativação e higienização do mesmo (Fig. 9A).

\section{DETALHES DA CONFECÇÃO Adaptação das bandas}

O primeiro procedimento consiste na seleção e na adaptação das bandas pré-contornadas nos dentes selecionados. Originalmente, como era um dispositivo indicado para dentição permanente, o aparelho disjuntor tipo Haas era ancorado nos primeiros pré-molares e nos primeiros molares superiores.

No estágio de dentição mista, os primeiros molares permanentes (Fig. 3B,C,D) ou preferencialmente os segundos molares decíduos (Fig. 3A) são os dentes de escolha ${ }^{19}$. Há indícios de pontos de reabsorção externa nas superfícies vestibulares das raízes de dentes de ancoragem, após a disjunção palatina ${ }^{2}$. Entretanto, outros estudos sugerem que existem processos de reparo, que corrigem ou estabilizam este quadro ${ }^{13}$. Fundamentado nessas observações histológicas é prudente optar, quando possível, pela bandagem dos segundos molares decíduos, para evitar que efeitos iatrogênicos se instalem nos dentes permanentes.

\section{Transferência das bandas}

Após serem selecionadas e adaptadas, realizar a transferência das bandas para a obtenção do modelo de trabalho. Com um alicate removedor de banda, a banda é retirada do dente e posicionada no alginato, uma a uma (Fig. 4A). É preciso atenção para não inverter as posições das bandas na moldagem. Um detalhe que auxilia muito a identificação e o seu posicionamento preciso consiste na soldagem de acessórios na face vestibular das bandas (Fig. 4A). Isto também pode ser feito com uma marcação com lápis dermatográfico ou caneta hidrográfica nas faces vestibulares, discriminando os lados direito (D) e esquerdo (E) das bandas.

\section{Fixação das bandas no molde de alginato}

Com as bandas já corretamente posicionadas, deve-se depositar pequenas porções de cera rosa super-aquecida (Fig. 4A,B), com o auxílio de uma espátula Lecron, nas superfícies palatinas internas e externas das bandas e em contato com o alginato. Isto aumenta a retenção, evitando que a banda se desloque do alginato durante os movimentos vibratórios no ato de vazar o gesso. Outra vantagem deste procedimento é a criação de um espaço no modelo de trabalho, entre a banda e o gesso, o que facilita o escoamento da solda, diminuindo o tempo da fase de soldagem e os riscos da perda das propriedades físicas desejáveis do fio de aço e da solda que compõem as barras de conexão palatinas (Figs. 4C-E).
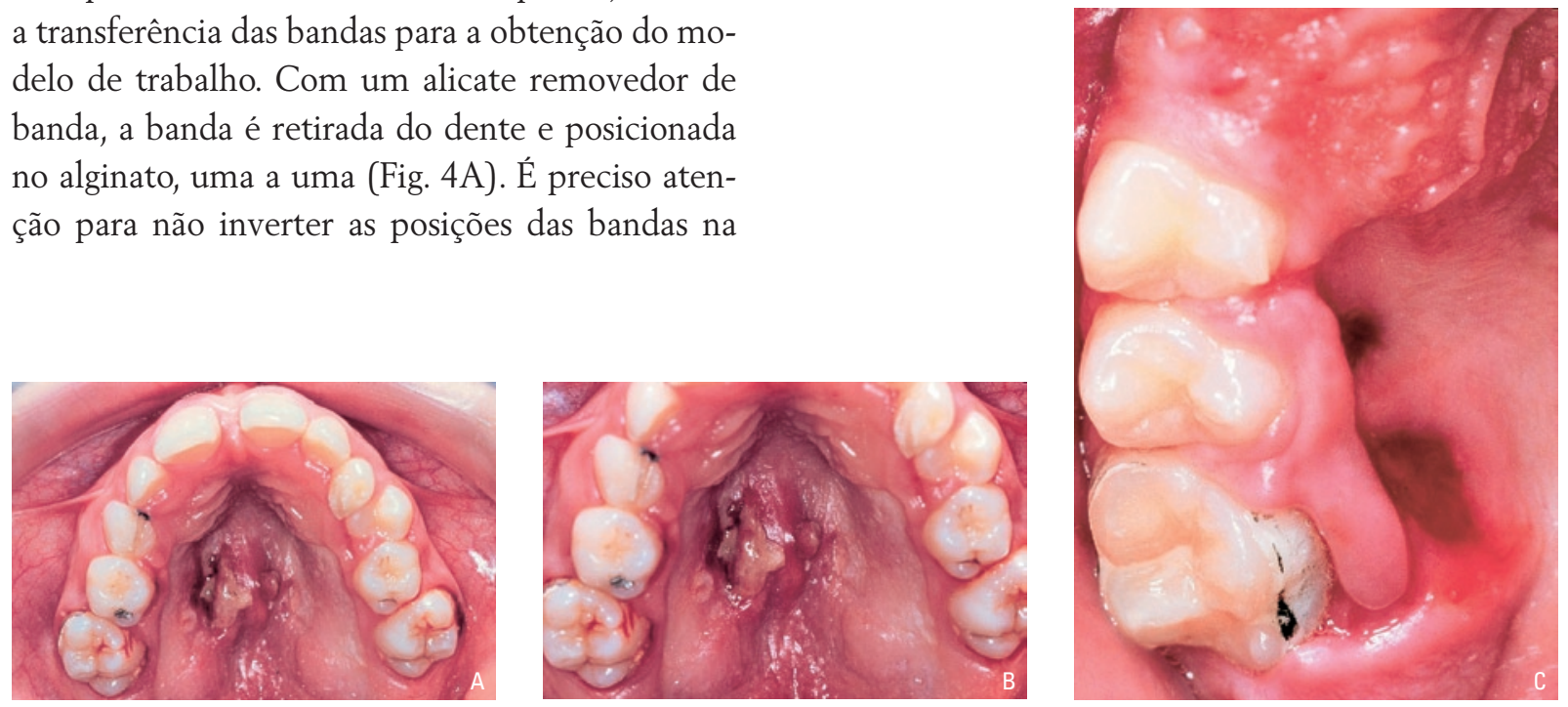

FIGURA 5 - Inflamação da mucosa da abóbada palatina devido à ruptura da solda provendo a compressão do acrílico, implicando na remoção do disjuntor palatino. 

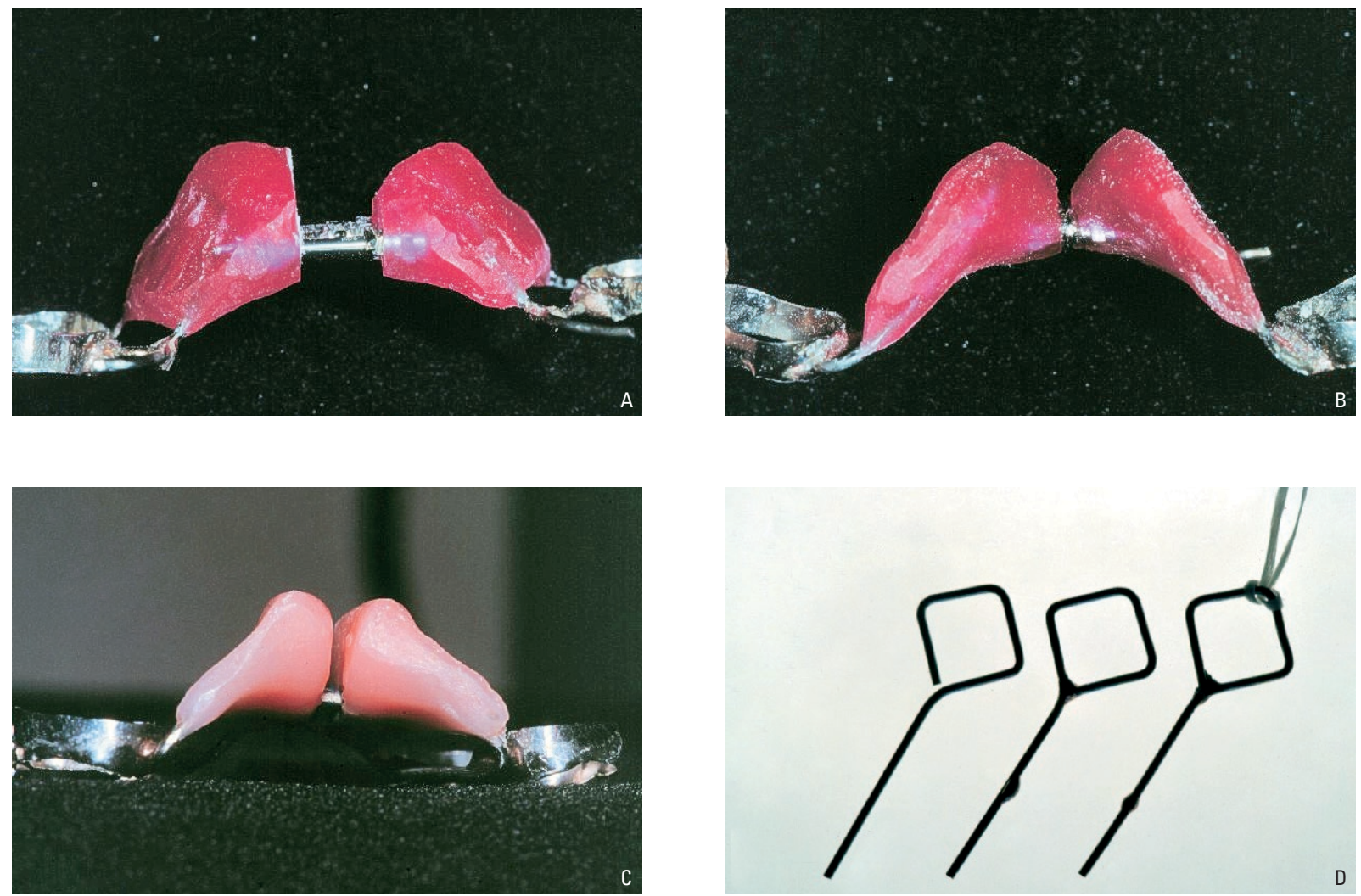

FIGURA 6 - A) Vista posterior do disjuntor aberto com o detalhe do acabamento na face interna esquerda. B e C) Vista posterior do disjuntor fechado e com o detalhe do acabamento nas faces internas. D) Passos da soldagem de um stop para regular o comprimento da parte ativa e evitar a introdução inadequada no momento da ativação.

\section{Soldas envolvendo toda a barra estabilizadora}

A fase de soldagem é um dos momentos cruciais para a resistência e a durabilidade do disjuntor. Mesmo em soldas consideradas bem feitas, o índice de fraturas é elevado ${ }^{12}$. O principal ponto de fratura está entre a banda e a barra da conexão palatina, região que deverá resistir aos esforços mastigatórios por três meses, tempo mínimo de contenção que o disjuntor deverá permanecer na boca, além do período de ativação do mesmo. Portanto, é fundamental que a solda se apresente como um bloco maciço, sem porosidades, e que envolva completamente toda a face palatina externa da banda e o fio a ela justaposto, em uma extensão próxima aos espaços interdentários mesial e distal aos molares. Para que estas premissas sejam atingidas, a área a ser soldada deve estar livre de substâncias externas e o fluxo deve ser uniformemente espalhado por toda a área a ser coberta pela solda (Fig. 4D-3F).

\section{Detalhes do parafuso}

Como há uma diversidade de tipos e marcas e também há falta de um padrão de qualidade institucionalizado pelo governo ${ }^{11}$, os parafusos têm capacidades variadas de expansão. No momento da inserção do parafuso no interior do acrílico, a orientação da seta deve estar voltada para distal (Fig. 4J, $\mathrm{N}, \mathrm{O}$ ). Uma vez construído, recortado e polido, o aparelho deve passar por uma avaliação da quantidade de ativações que é capaz de fornecer. Para isso, com a chave de ativação, promove-se a sua abertura total, fazendo a contagem do número de $1 / 4$ de volta que aquele parafuso é capaz de oferecer (Fig. 4K). Nas ativações finais, deve-se ter o cuidado para não espanar o parafuso (Fig. 4L). Além de revelar a capacidade expansora do aparelho, esse detalhe também possibilita que o profissional possa estipular um protocolo preciso de ativações e programar os intervalos para o retorno do paciente. Os parafusos 
da Dentaurum ${ }^{\circledR}$ apresentam uma trava no final da rosca do parafuso que impede o seu retorno. Isso deve ser levado em consideração antes de esgotar as ativações do parafuso expansor.

\section{Arredondamento do acrílico}

O apoio de acrílico, justaposto à abóbada palatina, pelo contato íntimo comprime a mucosa durante a fase ativa da expansão e deixa no palato a sua impressão. Ao retirar o aparelho essas compressões, via de regra assintomáticas, são identificadas como aprofundamento na mucosa do palato que podem vir acompanhadas de diferentes graus de inflamação (Fig. 5A, C). Para alívio preventivo do paciente aconselha-se o arredondamento por desgaste de todas as arestas do apoio de acrílico, eliminando as bordas em ângulo vivo. O arredondamento deve ser feito após o teste do parafuso (Fig. 6A, C). No entanto, essa compressão adquire importância a partir da adolescência, quando reflete descompasso entre a velocidade de ativação e a liberação do efeito ortopédico na maxila e a sua magnitude pode trazer grande desconforto para o paciente, com inflamação, edema e necrose do palato, normalmente acompanhado de sintomatologia dolorosa ${ }^{3}$.

\section{Chaves com stops}

A chave de ativação que acompanha os parafusos expansores vem de fábrica como um fio de aço, de grosso calibre, dobrado para facilitar o manuseio, porém, se for utilizado como é apresentado comercialmente, a chave poderá passar pelo parafuso, atingindo a mucosa do palato, e causar danos severos no momento da ativação. Para se evitar isto, deve-se colocar uma porção de solda na altura média da chave, que irá funcionar como um stop (Fig. 6D), impedindo que a mucosa palatina seja ferida. Pode-se aproveitar esta ocasião para soldar as extremidades que compõem o cabo da chave, pois há, também, o perigo de ocorrer deglutição acidental durante o procedimento de ativação. A manobra de escolha para impedir essas iatrogenias é unir o cabo da chave ao punho da pessoa responsável pelas ativações com uma tira de fio dental ${ }^{16}$, ou mais apropriadamente com cordonê.

\section{DETALHES CLÍNICOS Cimentação}

O material de escolha para a fase de cimentação é o ionômero de vidro, devido à boa propriedade de retenção da banda à estrutura dentária e às suas propriedades preventivas de liberação de flúor ${ }^{15,17}$. Previamente à instalação do aparelho, deve-se fazer uma profilaxia, com escova de Robinson e/ou taça de borracha, pedra-pomes e água, em todos os dentes superiores que servirão como elementos de ancoragem para o disjuntor. Com o propósito de verificar a adequada adaptação do aparelho ao arco superior, realiza-se a prova do mesmo antes de sua cimentação definitiva, para avaliar a adaptação das bandas, a adequada justaposição do acrílico ao palato e o contorno preciso da estrutura metálica nos dentes de ancoragem ${ }^{4}$. Após constatada a boa adaptação do aparelho e antes da cimentação, deve-se colocar tiras de fita adesiva sobre as bandas para que, no momento da inserção, o cimento escoe em direção ao sulco gengival, promovendo uma película uniformemente espalhada por toda a interface dente-banda.

\section{Colagem}

Nos casos de dentição decídua e mista, antes da cimentação, pode-se promover um despolimento da parte da estrutura metálica que ficará apoiada sobre os dentes decíduos, para melhorar a retenção mecânica. Após a cimentação das bandas posteriores, remove-se qualquer resíduo de saliva na superfície palatina dos dentes decíduos que serão colados à estrutura metálica e realiza-se o condicionamento ácido destas superfícies. O ácido é, então, lavado e os dentes, secos. Uma quantidade de resina é inserida, de modo a cobrir o fio em direção oclusal e gengival e penetrar entre o fio e a superfície dentária. Então, um pequeno acabamento é feito para evitar espículas traumatizantes de resina (Fig. 3A,B, 10B,C). 

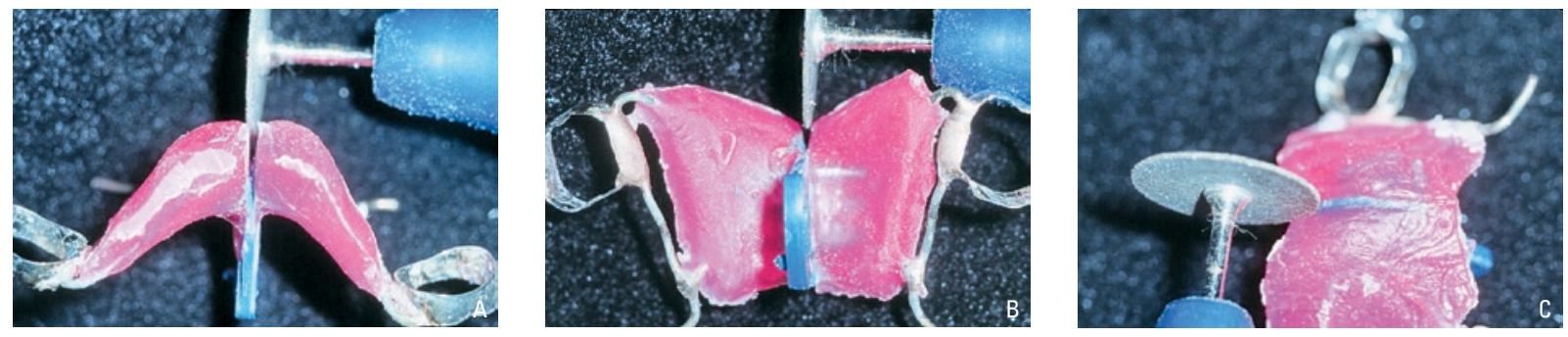

FIGURA 7 - Recorte do acrílico abaixo e acima do plástico protetor do parafuso com o disco de carboril ou carborundum. Cuidar para não cortar o parafuso.
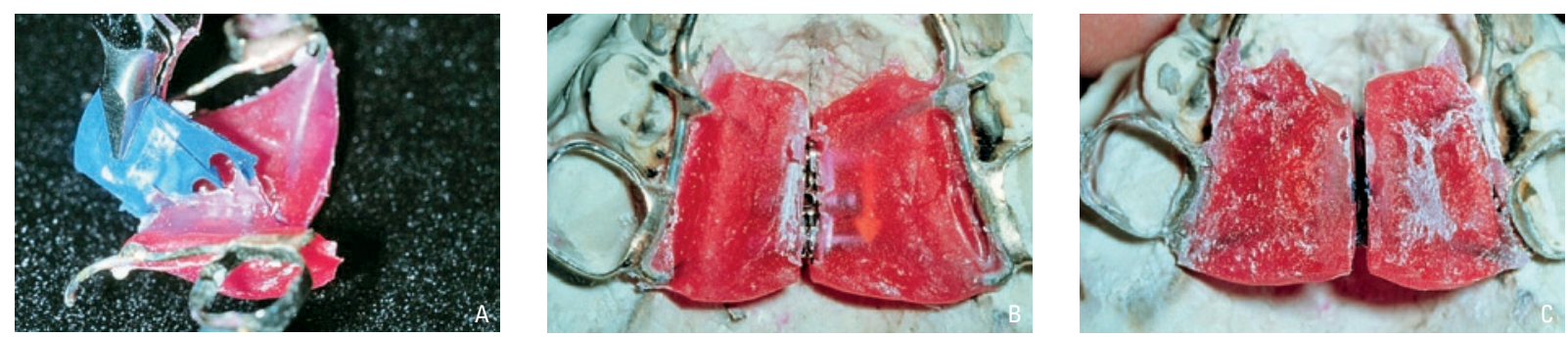

FIGURA 8 - A) Remoção do plástico protetor com o auxílio do alicate bico chato ou o de Young. B e C) Aspecto externo e interno do disjuntor palatino após a remoção do plástico protetor e antes do acabamento e polimento final.
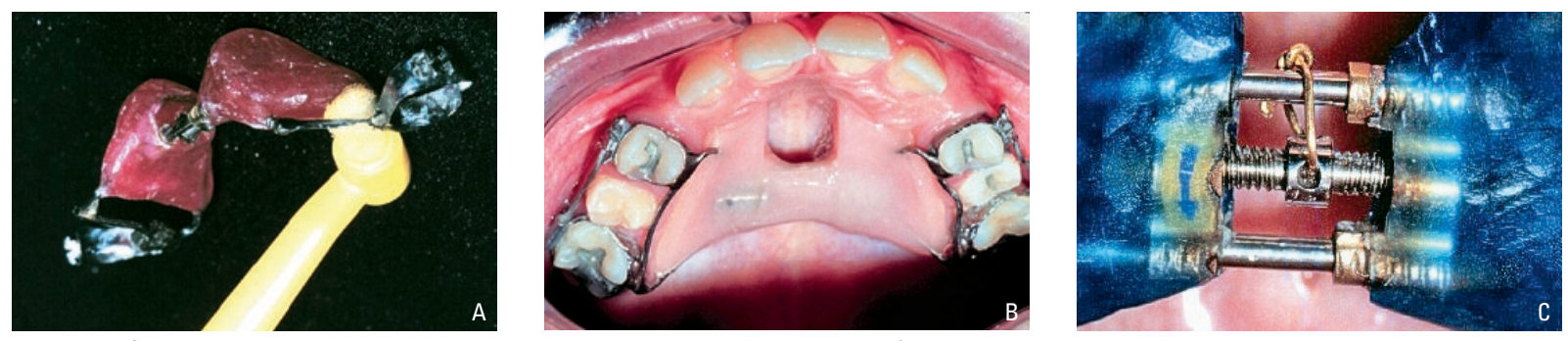

FIGURA 9 - A) Escova bitufo para facilitar a escovação entre a barra de conexão e o acrílico. B) Contenção do parafuso, após obtido o descruzamento desejado, com acrílico autopolimerizável. C) Contenção do parafuso com fio de separação de dentes.
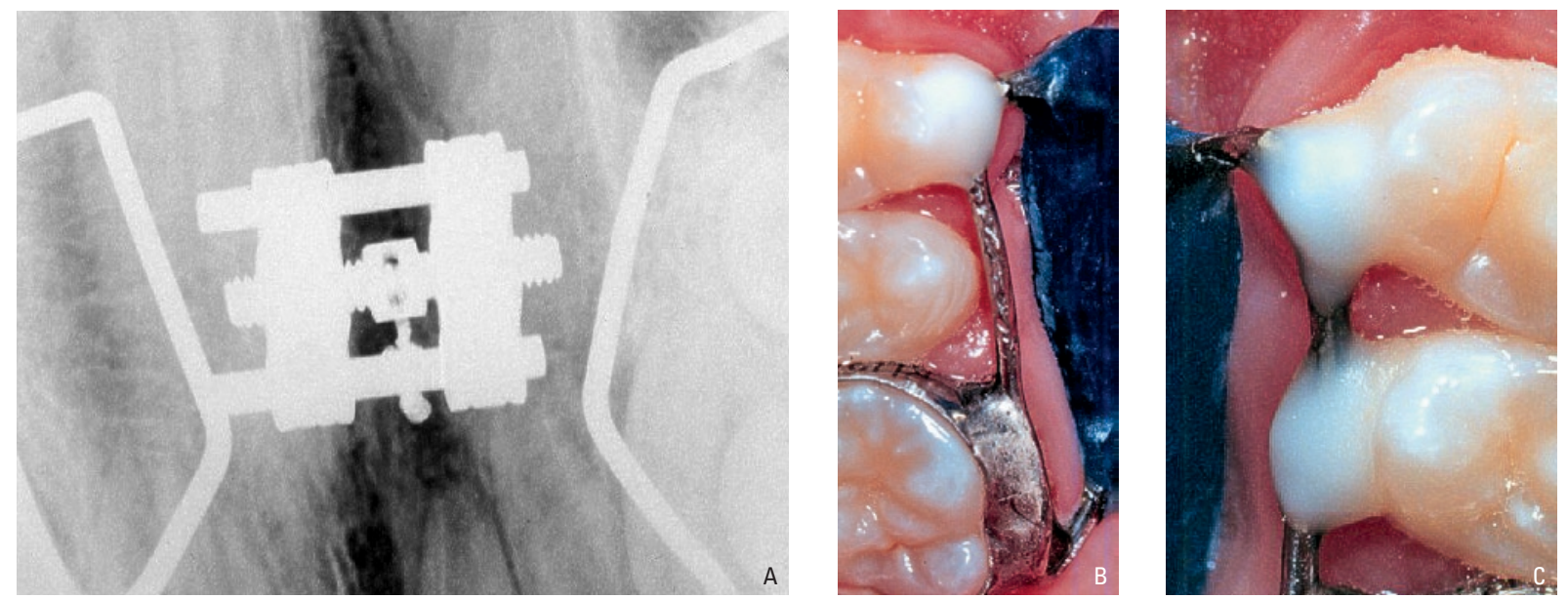

FIGURA 10 - A) Imagem radiográfica (oclusal) com o fio de estabilização. B) Detalhe da resina fotoativada no $1^{\circ}$ pré-molar superior direito. C) detalhe da fixação nos $1^{\circ}$ e $2^{\circ}$ pré-molares. 


\section{Higienização (bitufo, bochechos)}

A higiene bucal é imprescindivel, para evitar acúmulo excessivo de placa, quando um aparelho como o disjuntor palatino for utilizado. Foi mostrado que a presença de aparelhos ortodônticos comprometem a qualidade da higienização ${ }^{14}$. Existem trabalhos que afirmam que somente a escovação normal e interdental é suficiente para reduzir e prevenir a inflamação gengival (Fig. 9A). Entretanto, o acesso das cerdas é praticamente impossível nas áreas entre o acrílico e a mucosa e na região abaixo das áreas soldadas entre as bandas e a estrutura metálica. Por isso, métodos complementares de higiene são necessários. Colutórios bucais, à base de clorexedina, têm mostrado bons resultados na diminuição da placa bacteriana e na diminuição do sangramento e da inflamação gengival, em pacientes sob tratamento ortodôntico ${ }^{1}$. Há também um método específico para remover resíduos alimentares alojados entre palato e acrílico. Este consiste no preparo de uma solução composta de três partes de água oxigenada e uma de água, que será injetada sob forte pressão, com o auxílio de uma seringa hipodérmica, na região das rugosidades palatinas, entre a mucosa e o acrílico, e, também, na região posterior, sob as áreas soldadas. Devese alertar o paciente sobre o risco da deglutição dessa solução.

\section{Ativação}

O protocolo descrito supõe que o profissional tenha bom senso clínico para utilizar aparelhos de ancoragem máxima, que sempre incluam fixação dentária rígida, com apoio dento-muco suportado, o tipo Haas. O protocolo de ativação do parafuso, em pacientes com até 14 anos, é de quatro ativações iniciais $(1 \mathrm{~mm})$, duas ativações $(1 / 2 \mathrm{~mm})$ por dia; em pacientes entre 15 e 18 anos, duas ativações iniciais e uma ativação por dia; de 20 a 25 anos, uma ativação inicialmente e uma ativação dia sim, dia não; mais de 25 anos uma ativação ini- cialmente e uma ativação dia sim, dia não, com cautela, pois em caso de desconforto, o parafuso é ativado duas vezes por semana. O conforto é sempre o ponto de referência na determinação do protocolo. Se houver dor, deve-se passar para o próximo protocolo, utilizado em pacientes com idades maiores ${ }^{10}$.

\section{Contenção}

Após obtida a expansão desejada, as ativações são suspensas e o disjuntor é mantido na boca por no mínimo 3 meses, tempo necessário para a neoformação óssea da sutura palatina mediana. Para evitar que o parafuso retroceda e cause recidiva, deve-se fazer a chamada contenção. Esta pode ser feita, amarrando-se os orifícios, utilizados para as ativações aos braços expansores do parafuso, com uma ligadura de amarrilho de $0,12 \mathrm{~mm}(.030$ "), ou ainda com fio de latão (Fig. 9C, 10A). Existe também a possibilidade de preenchimento do espaço do parafuso com resina acrílica, inserida com a técnica do pincel (Técnica de Nealon). Para esta técnica, é necessário um pincel pequeno e pequenas porções de monômero e polímero acondicionados em 2 potes dappen. O pincel é embebido em monômero, sendo, então, incorporado ao polímero. Então, leva-se o pincel com monômero e polímero até os orifícios do parafuso. Repete-se o procedimento até que o parafuso seja completamente coberto pelo acrílico (Fig. 9B), tomando o cuidado para que não haja deglutição do material. Para impedir isso, coloca-se um espelho bucal entre o disjuntor e a orofaringe.

\section{Recomendações ao paciente e/ou responsável}

Orientar o paciente, pais ou responsáveis sobre o fato de que, no dia da instalação do disjuntor o(a) paciente poderá sentir alguma dificuldade durante o momento da alimentação, principalmente durante a deglutição dos alimentos, porém, gradualmente, ocorrerá a adaptação. 


\section{CONCLUSÕES}

A disjunção palatina, como um todo, não é um procedimento ortodôntico simples. Até que os objetivos transversais sejam alcançados, os pequenos detalhes devem ser rigorosamente observados e aplicados criteriosamente com conhecimento científico das causas e conseqüências.

\title{
Singular aspects to operate rapid palatal expansion procedures
}

\begin{abstract}
The rapid maxillary expansion procedure provide significant benefits in malocclusions with esqueletal posterior crossbites. Since Angell, lots of manuals were made in effort to guide the assembly of appliances from different types and employment of several techniques to obtain the desired correction. The technology used to improve the appliance materials is very important, but little details that actually are not so small together with scientific acknowledge and good sense must be regarded because one can not wait for the appliance "to do and solve" everything, correcting the posterior cross bites by a sleight-of-hand trick. The purpose of this report is to detail some little global aspects about construction, activation and concerns during the permanence period of the rapid maxillary expansion appliance in the mouth.
\end{abstract}

Key words: Palatal expansion. Hass appliance. Rapid maxillary expansion

\section{REFERÊNCIAS}

1. ANDERSON, B. G. et al. Clinical effects of chlorhexidine mouthwashes on patients undergoing orthodontic treatment. Am J Orthod Dentofacial Orthop, St. Louis, v. 111, no. 6, p. 606-612, June 1997.

2. BARBER, A. F.; SIMS, M. R. Rapid maxillary expansion and external root resorption in man: An SEM study. Am J Orthod, St. Louis, p. 630-652, v. 79, no. 6, June 1981.

3. CAPELOZZA FILHO, L.; CARDOSO NETO, J.; SILVA FILHO, O. G.; URSI, W. J. S. Non-surgically assisted rapid maxillary expansion in adults. Int J Adult Orthod Orthognath Surg, Lombard, v. 11, no.1, p. 57-66, 1966.

4. CAPELOZZA FILHO, L.; REIS, S. A. B.; CARDOSO NETO, J. Uma variação no desenho do aparelho expansor rápido da maxila no tratamento da dentadura decídua ou mista precoce. R Dental Press Ortodon Ortop Facial, Maringá, v. 4, no.1, p. 69-74, jan./fev. 1999.

5. DEBBANE, E.F. A Cephalometric and Histologic Study of the Effect of Orthodontic: Expansion of the Midpalatal Suture of the Cat. Am J Orthod, St. Louis, v. 44, p.187-218, 1958

6. HAAS, A. J. Gross reaction to the widening of the maxillary dental arch of the pig by splitting the hard palate.1953. $36 \mathrm{f}$ Master Thesis, Chicago, 1953

7. HAAS, A. J. Palatal expansion: just the beginning of dentofacial orthopedics. Am J Orthod, St. Louis, v. 57, no. 3, p. 219-255, Mar. 1970.

8. HAAS, A. J. Rapid expansion of the maxillary dental arch and nasal cavity by opening the midpalatal suture. Angle Orthod, Appleton, v. 31, no. 2, p.73-90, Apr.1961.

9. HAAS, A. J. The treatment of maxillary deficiency by opening the midpalatal suture. Angle Orthod, Appleton, v. 35, no. 3, p. 200-217, July 1965
10. HAAS, A. J. Entrevista. R Dental Press Ortodon Ortop Facial Maringá, v.6, n.1, p.1-10, jan./fev. 2001.

11. INMETRO. Produtos analisados. Disponivel em: $<h t t p: / / w w w$. inmetro.gov/cs_produtos.htm>. Acesso em: 9 maio 2001.

12. KUERER, B. The broken solder joint: causes and treatment Dent Survey, Minneapolis, v. 55, p. 28, 1979.

13. LANGFORD, S. R.; SIMS, M. R. Root surface resorption, repair, and periodontal attachment following rapid maxillary expansion Am J Orthod, St. Louis, v. 81, no. 2, p.108-115, Feb. 1982.

14. LUNDSTRÖM, F.; HAMP, S.E. Effect of oral hygiene education on children with and without subsequent orthodontic treatment. Scand J Dent Res, Copenhagen, v.88, p. 53-59, 1980.

15. MAIJER, R.; SMITH, D. C. A comparison between zinc phosphate and glass ionomer cement in orthodontics. Am J Orthod, St. Louis, v. 93, no. 4, p. 273 - 279, Apr. 1988.

16. NAZIF, M. M.; READY, M. A. Accidental swallowing of orthodontic appliance keys: report of two cases. J Dent Child, Chicago, v. 50, p.126-127, 1983

17. NORRIS, D.; LEDOUX, P.; SCHWANGER, B.; WEINBERG, R. Retention of new orthodontic bands with new fluoride releasing cements. Am J Orthod, St. Louis, v. 89, no. 3, p. 206-211, Mar. 1986.

18. SILVA FILHO, O. M. et al. Expansão ortopédica da maxila em estágios precoces do desenvolvimento oclusal: confecção laboratorial e apresentação de caso clínico. Rev Bras Odontol, Rio de Janeiro, v. 46, n. 3, p. 25-34, nov./dez. 1989.

19. SILVA FILHO, O. G.; FERRARI Jr., F.M.; AIELLO, C. A.; ZOPO$N E, N$. Correção da mordida cruzada posterior nas dentaduras decídua e mista. Revista APCD, São Paulo, v. 54, n. 2, p. 142147, mar./abr. 2000.

20. TIMMS, D. J. The dawn of rapid maxillary expansion. Angle Orthod, Appleton, v. 69, no. 3, p. 247-250, 1999.

Endereço para correspondência

Orlando Tanaka

Rua Mal Deodoro, 630, 1703

CEP: 80010-912 - CURITIBA-PR

Email: tanaka.o@pucpr.br / Site: www.tanaka.com.br 